Recepción: 10/ 03 / 2018

Aceptación: 15 / 04 / 2018

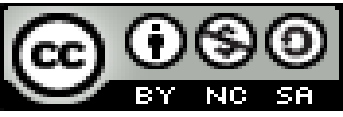

Ciencias de la educación

Publicación: 01 / 08 / 2018

Artículo de investigación

\title{
Ensayo bibliográfico descolonizar la docencia Universitaria Ecuatoriana
}

\author{
Bibliographic essay decolonizes Ecuadorian University Teaching
}

Ensaio bibliográfico descoloniza o ensino da Universidade de Ecuatorian

\author{
Teresa Vargas-Cevallos ${ }^{\mathrm{I}}$ \\ heidy151@hotmail.com \\ Lenin Mendieta-Toledo ${ }^{\text {III }}$ \\ lenin.mendietat@ug.eduec
}

Correspondencia: heidy151@ hotmail.com

${ }^{\text {I }}$ Docente Instituto Ana Paredes Alfaro, Guayaquil, Ecuador.

III Magister en Docencia Universitaria e Investigación Educativa, Máster Universitario en Actividad Física y Salud, Licenciado en Ciencias de la Educación en la Especialidad de Educación Física, Docente Universidad de Guayaquil, Guayaquil, Ecuador. 


\section{Resumen}

El objetivo del ensayo fue determinar si existe la posibilidad de una descolonización de la docencia universitaria ecuatoriana, para ello se analizaron cuatro obras académicas de reconocidos sociólogos, se hizo un diálogo imaginario para establecer la relación entre estos y las propuestas de los mismos. Se realizó una introducción como hoja de ruta a seguir en el desarrollo del ensayo, se rescataron las improntas de los autores y el pensamiento descolonizador de cada uno de ellos, desde la descolonización de la economía política, el pensamiento fronterizo y la colonialidad global; la Bios, el poder y la política desde un enfoque decolonial crítico de la educación; Decolonizar la universidad; y Decolonizar el saber, reinventar el poder. Se concluyó que no es posible la decolonización de la docencia universitaria ecuatoriana por cuanto la misma carece de identidad académica, no existe un perfil epistemológico que permita diseñar currículos independientes del sistema Estatal y con ello se sigue cayendo en el eurocentrismo.

Palabras clave: decolonización, biopoder; docencia universitaria; identidad académica; perfil epistemológico del docente.

\section{Abstract}

The purpose of the essay was to determine if there is a possibility of a decolonization of Ecuadorian university teaching, for which four academic works of well-known sociologists were analyzed, an imaginary dialogue was made to establish the relationship between these and their proposals. An introduction was made as a roadmap to follow in the development of the essay, the imprints of the authors and the decolonizing thought of each of them were rescued, from the decolonization of political economy, border thinking and global coloniality; Bios, power and politics from a critical decolonial approach to education; Decolonize the university; and Decolonize knowledge, reinvent power. It was concluded that the decolonization of Ecuadorian university teaching is not possible since it lacks an academic identity, there is no epistemological profile that allows for the design of independent curricula of the State system and with this, Eurocentrism continues to fall.

Key words: decolonization; biopower; university teaching; academic identity; teacher's epistemological profile. 


\section{Resumo}

O objetivo do teste era determinar se existe a possibilidade de descolonização do ensino universitário equatoriana, por isso quatro trabalhos acadêmicos por sociólogos de renome analisados, tornou-se um diálogo imaginário para estabelecer a relação entre estes e as propostas para eles. Uma introdução foi feita como um roteiro a seguir no desenvolvimento do ensaio, as impressões dos autores e descolonizar o pensamento de cada um deles resgatados da descolonização da economia política, pensamento de fronteira e da colonialidade global; Bios, poder e política de uma abordagem descolonial crítica para a educação; descolonizar a universidade; e descolonizar o conhecimento, reinventar o poder. Concluiu-se que não é possível descolonização do ensino universitário equatoriano porque não tem identidade acadêmica, há um perfil epistemológico que permite currículos independente do projeto do sistema estatal e, assim, continua a cair em eurocentrismo.

Palavras chave: descolonização; biopoder; ensino universitário; identidade acadêmica; perfil epistemológico do professor.

\section{Introducción}

La falta de identidad y competencias de los docentes en el nivel superior, como el arjé de la problemática educativa-social, es una dimensión ontológica subjetivada para no ver desde la profundidad del objeto, al ente gregario formado por el sistema como "docente" para formar una sociedad enajenada y neo-colonizada para la continuidad de la explotación. La docencia está sitiada y vive bajo una colonialidad y está cómoda en ese nicho en el que la ha ubicado el sistema de biopoder.

La deconstrucción de objeto que se realiza en los próximos párrafos tiene su base en los contenidos de cuatro obras sobre la decolonización y descolonización del objeto y sujeto en la educación contemporánea, estas obras son trabajadas y llevadas al contexto educativo en el Ecuador del siglo XXI. Abordado desde el análisis de los escritos de Ramón Grosfoguel (2006) "La descolonización de la economía política y los estudios postcoloniales: Transmodernidad, pensamiento fronterizo y colonialidad global"; Graciela Flores "Bios, poder y política. Una perspectiva desde el enfoque decolonial crítico de la Educación"; Santiago Castro-Gómez 
"Decolonizar la universidad: La hybris del punto cero y el diálogo de saberes"; y, Boaventura de Souza Santos con la obra Decolonizar el saber, reinventar el poder"

En los párrafos que próximos posteriores cometamos y analizamos el contenido de tres artículos, basado el primero en la necesidad de descolonizar la economía, se continua con los artículos de Graciela Flores y Santiago Castro sobre la decolonización de la educación y se dejó para el final el libro de Boaventura de Souza de decolonizar el saber. Lo que pretendemos es hacer un diálogo entre los autores que nos permitan entender como la economía política colonizadora ha sido el artífice de un colonialismo cognitivo, constriñendo el pensamiento autónomo y libre que en algún momento histórico tuvo nuestra América India, se pasa por en análisis crítico de la educación tratando de visualizar desde la idea de Flores la forma de decolonizar nuestra identidad bioantropológica, tomando como base para ello la decolonización de la universidad que plantea Santiago Castro mediante el dialogo de saberes.

El desarrollo del ensayo se circunscribe en un espacio bien definido y organizado según nuestra elemental lógica racional -1. la descolonización de la economía política y los estudios postcoloniales; 2. Bios, poder y política. una perspectiva desde el enfoque decolonial crítico de la educación; 3. decolonizar la universidad; 4. decolonizar el saber, reinventar el poder- para tratar de entender los saberes de los autores: se tomaron en el orden establecido los trabajos, se describen las ideas principales de cada uno y se discuten las mismas; se manejan dos hebras para el análisis: una temática -que será abordada- y otra conceptual -se encuentran insertadas como notas al final-, las mismas se entrelazan al final sin pretender bifurcar la idea y esencia de cada uno de los autores, sino con el ánimo de aportar desde nuestra nimiedad cognitiva, un punto de vista impío, irreverente y atrevido sobre estos saberes tan bien trabajados por los autores y tratar de extrapolarlos o contextualizarlos a la docencia superior ecuatoriana.

La hebra temática versa sobre la descolonización del saber, la decolonización de la universidad y la descolonización del poder mediante la decolonización de la academia -ecuatoriana- para construir una nueva realidad autónoma pero basada en la complementariedad, reciprocidad y redistribución entre nuestro arjé indígena y lo colonial benéfico impregnado desde hace más de 500 años y que se ha convertido en sustancial en nuestras vidas. 
La hebra conceptual se va hilvanando con algunas ideas comunes de los autores y definiciones de la RAE y del diccionario AKAL de filosofía, definiciones de términos utilizados por los autores, los mismos que se irán señalando en las notas al final para que el lector pueda transitar a través de un vector coherente y con la complementariedad que amerite cada definición o pensamiento. Cómo se define la recolonización, descolonización o decolonización, partiendo de la idea de colonización en término general y llegando a la colonización del saber para subyugarnos con el poder dominante desde la fuerza hasta las letras enajenantes que nos mantienen oprimidos durante siglos y hasta nuestros días. Llegar a razonar hasta qué punto es permitido por los docentes de la academia de neo-colonización de la sociedad mediante el uso indiscriminado de currículos -conceptos y paradigmas- creados para nuestra sociedad, mientras los otros transitan por el supra-conocimiento y a nosotros nos lanzan los retazos de un objeto de conocimiento obsoleto y tejido puntada tras puntada para la continuidad de la explotación y esclavitud cognitiva. Por último, trazamos un perfil con las fortalezas y debilidades de los artículos y libros analizados y se las compara entre sí y con algunos requisitos previos del autor con citas ajenas a los textos estudiados.

La parte de las conclusiones se emiten desde el entendimiento de los textos y basada en una crítica no solapada del sujeto que habla tratando de posicionarnos con una firme postura desalienante decolonizadora, pero con compostura académica, sin perder la esencia que nos hace estar aprendiendo en cada seminario al que asistimos en nuestro proceso formativo de toda la vida. Estas conclusiones se posicionan por supuesto, en el contexto educativo ecuatoriano en el nivel superior para dar cumplimiento y sentido al título que es "Decolonizar la docencia universitaria ecuatoriana". Aquí es donde nosotros entramos a buscar el intersticio desde donde se pueda ver la luz que nos permita identificar si es posible "decolonizar la docencia universitaria ecuatoriana".

\section{Desarrollo}

La descolonización de la economía política y los estudios postcoloniales: transmodernidad, pensamiento fronterizo y colonialidad global. 
El artículo de Grosfoguel (2006), plantea una perspectiva epistémica con enfoque subalterno de las formas de colonialismo, colonialidad y sus repercusiones que han trascendido a través cientos de años y que hoy se encuentran más ancladas que nunca en el subconsciente de nuestra Latinoamérica, sobre la forma de descolonizar mediante el análisis de los patrones superpuestos, y la búsqueda de una identidad subalterna desde el sur, sin injerencias eurocéntricas que están imbricadas en todos los estratos sociales -incluidos los académicos-, con un discurso autóctono y no el doble discurso sobre el objeto del conocimiento desde el sur con claras y demarcadas teorías situadas y trabajadas desde un eurocentrismo poscolonial.

La crítica pertinente que hace el autor sobre los pensadores latinoamericanos -llamados a liberar el sur desde una epistemología que nazca desde abajo y se encumbre hacia arriba- deja claro el sesgo de estos pensadores que ponen en el pedestal las teorías europeas. Grosfoguel (2006) enfatiza en que no se trata de criticar desde un nimio fundamento esencialista, fundamentalista, antieuropeo, sino que es un enfoque crítico del fundamentalismo, el colonialismo y el nacionalismo eurocéntricos para el tercer mundo, desde donde la verdad y universalidad del conocimiento es dado desde Europa para él mundo, sin embargo, este eurocentrismo basa su filosofía en un sujeto que habla desde el disfraz y la trinchera oculta, no da la cara ni se posiciona en un nicho desde donde pueda defender su verdad, sino que habita en su "Ego no situado", hay una ruptura no epistémica sino de autoría y defensa de tesis.

La crítica epistemológica de Grosfoguel (2006) se maneja desde una perspectiva subalterna raciales/étnicas y feministas, para tratar de romper los paradigmas eurocéntricos que mantienen su hegemonía hasta la fecha con una pseudo neutralidad, objetividad y universalidad del saber, no siendo más que un posicionamiento desde las estructuras de poder, en donde nadie se sale del coto establecido por el sistema mundo moderno/colonial capitalista/patriarcal, es decir el conocimiento está sitiado. Pero, la cuestión no radica solo en el contexto político y geográfico, sino también en el sujeto que habla. La cuestión que crítica el autor del artículo es que no se puede tener un posicionamiento epistémico subalterno de letras y discursos, sino debe constituirse en una estructura de conocimiento del objeto, de libertad mental y espiritual, solo en ese momento se romperá el yugo cognitivo que nos mantienen en estado de ostracismo. 
El eurocentrismo -aunque no se le conociera con ese nombre en ese espacio temporal- se supo manejar desde la época de Descartes cuando encumbró al hombre como dador del conocimiento incluso por encima de Dios, logrando reclamar un conocimiento no situado, universal y omnipresente, sin la necesidad de declararse "él Sujeto superior", lo hizo de forma solapada con los resultados esperados. Al poder imponer las teorías y conceptos, logró también la jerarquía oculta de gente superior e inferior -gente sin escritura a gente sin historia; gente sin desarrollo; gente sin democracia; pasando de los derechos del pueblo a los derechos del hombre y a los derechos humanos posteriormente-, sin embargo esto es solo la cara disfrazada del colonialismo y hoy y desde hace más de 500 años se vive el "conquisto, luego Soy europeo".

La colonialidad del poder como matriz de poder del mundo moderno/colonial es a día de hoy impuesta en cada teoría, concepto o idea que nace desde la iluminada visión del hombre occidental, la globalización no es global, ni la democracia es democracia, el capitalismo está dividido en jerarquías sociales, políticas y económicas, llegando de forma maquillada como verdad absoluta y universal al sur y sigue el proceso de neo-colonización. Para poder descolonizar el saber -y con ello el poder y el sistema mundo- debemos asumir una postura epistémica descolonizadora desde el objeto del conocimiento, esto se consigue desde algunas aristas que el autor trae a colación: la llegada a América del hombre europeo -con sus características cristianas, patriarcales, militares, heterosexuales y más...- con el sistema de explotación y enajenación -coexistencia de la riqueza/explotación; división del trabajo; jerarquización racial global, espiritual, epistémica, lingüística, sexual y de género- en donde todo lo occidental tenía rasgos de superioridad ante nosotros. Se puede resumir que la raza y racismo son los parámetros que miden los niveles de posicionamiento jerárquico del sistema mundo europeo moderno/colonial capitalista/patriarcal.

Paso del colonialismo global a la colonialidad global. - Grosfoguel (2006) aclara que no se puede pensar en tomarse el poder y con ello lograr la descolonización, señala que la independencia política de la colonia no sugiere el destete patriarcal arraigado en el constructo social de la población. Se pudo haber logrado la libertad del colonialismo, pero quedó la colonialidad global producto del colonialismo, el lograr la descolonización y descolonialidad no se manejan en tiempos iguales, lo primero se pudo lograr en 100, 150, o 200 años, pero lo segundo es como un 
cáncer que no se puede extirpar con bisturí y luego suturar, es mucho más que eso, es lograr que desde la escuela los niños aprendan a vivir esa descolonialidad, pero como lograrlo si los docentes se encuentran aún bajo los efectos de esa colonialidad.

Postcolonialidad y sistemas mundiales: un llamado al diálogo. - El autor señala "La crítica postcolonial caracteriza el sistema capitalista como un sistema cultural. Sus partidarios creen que la cultura es el elemento constitutivo que determina las relaciones económicas y políticas en el capitalismo global", es así como a pesar de los esfuerzos de los teóricos latinoamericanos no se puede descolonizar el pensamiento colonizado del más intelectual de los latinoamericanos, es preciso desarrollar un nuevo lenguaje descolonizador para dar cuenta de los complejos procesos en el sistema mundo moderno/colonial sin depender del viejo lenguaje liberal de los económico, político y sociocultural que está impregnado en lo más profundo del espacio cognitivo latinoamericano y seguirá por muchos años más, aún el día en que el norte sea el sur.

Pensamiento fronterizo. - Grosfoguel (2006) señala que la cultura occidental y con ella la economía y la política se ha impuesto mediante la colonia a las diferentes cosmologías y epistemologías del mundo no occidental. Es por ello que es necesario -argumenta el autortomando la idea de Mignolo, (2000) que se genere una idea subalterna al proyecto eurocéntrico, desde una redefinición del objeto con autonomía cognitiva, emancipatoria, liberadora de la ciudadanía, la democracia, los derechos humanos, la humanidad y las relaciones económicas pensamiento anti-moderno-. Descolonizar esa imposición -cristiana de redención, civilización y salvación del hombre blanco a nuestros indios y hasta ahora con la llamada lucha por la democracia y derechos humanos de las américas-, desde una nueva arista y no desde el fundamentalismo y nacionalismo con filosofías eurocéntricas impuestas subliminalmente mediante el diseño global/imperial/ que tiene marcada tendencia eurocéntrica, jerárquica, autoritaria y antidemocrática. Es mignolo, (2000) señala Grosfoguel (2006), quien presenta una propuesta subalterna arrimándose a una vera paradigmática decolonizadora pertinente desde un pensamiento fronterizo crítico, este pensamiento no es fundamentalista antimoderno, es más bien la respuesta descolonial transmoderna de lo subalterno a la modernidad eurocéntrica.

Transmodernidad o cosmopolitanismo crítico como proyectos utópicos. - En este contexto de la transmodernidad, Grosfoguel (2006) hace una reflexión del pensamiento de Dussel, en donde se 
pretende dar aviso a lo inoportuno y demagógico del falso diálogo entre el norte y el sur, falso pues no existe esa horizontalidad que pregonan, ni esa igualdad que pretenden hacer creer. Sin embargo, tanto Dussel como Grosfoguel (2006), plantean la idea de mundos alternativos sin injerencia eurocéntrica y fundamentalista, desde la multiplicidad de respuestas críticas descoloniales a la hegemonía eurocentristas planteando una respuesta subalterna con sólidas bases epistémicas o, lo que sería planteado por Mignolo en base a Dussel (2001) sobre una diversidad como proyecto universal, o el pensamiento fronterizo de Grosfoguel (2006) entendidos estos en su conjunto como la intervención insurrecta desde la episteme subalterna del objeto de conocimiento.

Las luchas anticapitalistas hoy. - Versa su discurso en un desmantelamiento de la dinámica colonial/racista, las cuales llegaron desde el eurocentrismo colonizarte en distintas épocas a distintos lugares, en todos los resultados fueron iguales, los movimientos de -pseudo- izquierda siguen manteniendo un statu quo jerárquico piramidal/racial y es por ello indica Grosfoguel (2006) que existe desilusión en la masa social. Lo que pretende el autor, es dar la pauta para que no pensemos que va a ser fácil dejar el colonialismo, pues estamos impregnados de él desde hace más de 500 años y está en nuestro subconsciente, la política de la identidad no podrá cambiar esos patrones que como marca oficial enajenante fueron impuestos en nuestro pensamiento, es decir por más que pretendamos descolonizarnos, los constructos coloniales están presentes. Una de las posibles soluciones sería, indica Grosfoguel (2006) trayendo al diálogo a Quijano, enarbolar la filosofía ancestral Andina e incluso de las nuevas comunidades marginales urbanas en donde la solidaridad y reciprocidad con sinónimos de vida comunitaria, desatendiendo los discursos neoliberales y neo socialistas ya que los dos pretenden que el estado sea la institución de autoridad pública. Para Grosfoguel (2006) analizando a Quijano, esto es una contradicción dialéctica con el desarrollo de un crecimiento alternativo "privado" y de los "individuos".

El autor termina esta parte manifestando que una forma de descolonización de la economía política del sistema mundo moderno/colonial capitalista/patriarcal sería la erradicación de la transferencia continua de riqueza del Sur al Norte y la institucionalización de la redistribución global y la transferencia de riqueza de Norte a Sur. 
Hacia un proyecto de "diversidad anticapitalista descolonial, universal y radical".- La descolonización requiere un lenguaje crítico sin el doble discurso, un lenguaje descolonizador global-local-universal, Grosfoguel (2006) llama a esta forma de universalidad una "diversidad radical universal descolonial anticapitalista" como proyecto de descolonización y liberación cimentado en una descolonialidad universal respetando las particularidades socio-contextuales, pero manteniendo una esencia ética-moral en la construcción epistémica, lo que representa para Grosfoguel (2006) una fusión entre la transmodernidad de Dussel (2001) y la socialización del poder de Quijano. Cierra el diálogo Grosfoguel (2006) indicando que es un llamado a crear un "universal que sea pluriversal, es decir, universal concreto: que incluiría todas las particularidades epistémicas hacia un universal que incluya todas las particularidades epistémicas hacia una socialización del poder descolonial transmoderna. Y termina con el pensamiento zapatista, "luchar por un mundo donde otros mundos sean posibles".

\section{Bios, poder y política. una perspectiva desde el enfoque decolonial crítico de la educación.}

Flores G., (2014) tiene una idea muy clara de lo que pretende con su escrito, coincide con el pensamiento decolonial en el sentido que es preciso recuperar la dignidad vital del sujeto, al cual lo instala tempranamente en el lugar que le corresponde -el sujeto es persona humana y no se puede colonizar o no se debe colonizar la vida humana- la autora se insubordina con el constructor de explotación impuesto por la colonia y postcolonia y que se mantiene en nuestros días. Critica firmemente la forma animal de dominio que existió y sus daños colaterales que perduran y afectan la vida como Bios, la naturaleza humana y la interferencia con su cultura. La autora utiliza el término biopoder que ejercen los estados para controlar la vida de los seres humanos con políticas cargadas de falsa solidaridad social a modo de anatomopolítica -desde la singularidad y la colectividad- con la llamada biopolítica. Graciela Flores recalca que la política es determinada por la vida y esta a su vez es penetrada por la política, una política colonial que bien puede ser enfrentada con el poder de la interioridad de la subjetividad y de las comunidades críticas. Termina manifestando que, si la vida fuese un objeto de poder positivo, entonces estaríamos ante un poder decolonial, por tanto, la educación debería involucrarse en la Transmodernidad como proyecto descolonizador. 
Lo que pretende Flores es instaurar insumos que permitan posicionarse en el ámbito educativo desde la decolonización, mediante la articulación de nociones interrelacionadas de vida-poderpolítica que permitan visualizar las incidencias de esta interrelación en el plano educativo -desde la óptica de cada lector-, la autora es convencida que la política está presente en la educación como potencia liberadora-, de igual forma, piensa que la educación debe ser la que demande la liberación del individuo concreto que se mantiene en estado de ostracismo frente al pensamiento impuesto y manejado como paradigmas dominantes. Dentro de estos insumos cita a Lleras quien es crítico y no se esconde al indicar que "la educación no plantea construir una sociedad de seres libres, sino formar seres sujetos a la racionalidad económica que no sean muy críticos y se sometan fácilmente a las propuestas generadas por las estructuras productivas y el sistema político".

Flores analiza dos posturas antagónicas -la primera busca la adaptación a las costumbres y prescripciones instituidas, la segunda la disconformidad con lo instituido y el criterio autárquico, sin los cuales no habría ni creatividad ni cambio-, estas posturas siempre van a estar presentes y será difícil lograr una posición neutral pues existen posturas que simplemente no pueden converger, no se pueden discutir, en este análisis también se presenta la propuesta de una educación involucrada en la transmodernización para la descolonización, es una visión decolonial que ve en el poder, colonialismo, e imperialismo el entramado de explotación y dominación político y por supuesto económico -con claras muestras de dominio de la vida de los individuos como persona particular y social-, es decir nos mantienen bajo un régimen biopolítico. Flores resalta en esta parte que no desecha el pensamiento de algunos europeos para no caer en un latino americanismo etnocéntrico.

Colonialidad y deshumanización: aportes para pensar una educación decolonial. - Flores toma la perspectiva decolonial crítica como bandera de lucha para la educación y para ello cola a Castro Gómez -a quien posteriormente lo analizaremos-, el cual afirma "la colonialidad del poder es la dominación que conlleva una transformación de la intimidad y de lo afectivo". Las transformaciones fueron lentas, poco a poco se arraigaron en la mente de los colonizados bajo el método de la coerción física y mental, ahora en nuestros días es aún difícil encontrar los intersticios que permitan salir de esa enajenación a la que fuimos sometidos. Para poder lograr 
esta descolonización de la vida es preciso prácticas biopolíticas decoloniales "masivas", en donde la educación sea proactiva desde los escenarios que le corresponden, para esto hay que redefinir la educación y su praxis social-formativa, que rescate nuestra dignidad vital.

Esta dignidad vital a la que se refiere Flores, permitirá recuperar la memoria histórica y la capacidad de actuar de forma autónoma y liberada del eurocentrismo, los responsables de esta tarea somos los maestros, para ello deberemos aprender a auto-hetero-decolonizarnos, con ello podremos reclamar: una diversidad universal en detrimento de la homogeneidad colonial, la reactivación de los objetos de conocimiento ancestrales que fueron discriminados para imponernos el saber occidental, una epistemología transformada o decolonizada. Esta tarea de descolonización primero de parte de los docentes, permitirá enseñar con confianza humanista, antropológica u ontológica, en aras de una rehumanización del ser, una confianza en nosotros como docentes y en ellos como alumnos, confianza en el potencial humano que permanece dormido a la espera de ser despertado en la luz de un nuevo saber, en palabras de Dussel indica Flores "Nuestra preocupación prioritaria es la vida, como valor que hay respetar y recuperar". Para cerrar este párrafo Flores toma la expresión de Fanon, "la descolonización es creación de hombres nuevos". Aquí aclara la Flores que es el hombre quien se re-crea mediante un proceso de liberación.

Flores se decanta por llamar al humanismo, transhumanismo, movida por las críticas de Heidegger al humanismo quien les atribuye el mérito de la interrogante “¿Qué amansará al ser humano, si, después de todos los experimentos que se han hecho con el género humano, sigue siendo incierto a quién o a qué educa y para qué el educador?”. Es aquí donde Flores asegura una vez analizada la interrogante de Heidegger que la educación y el humanismo han fracasado, luego continua y cambia el discurso con un "creemos en la educación y estamos convencidos de que la pedagogía decolonial tiene claro a quién y para qué educa el educador que suscribe a este enfoque". El humanismo tiene su origen en la vida humana y por ello le denomina Biopoder de la colonialidad, que es la explotación en cualquiera de sus manifestaciones del hombre al hombre -objetivado, cosificado-, ejemplifica que el racismo colonial -es igual en cualquier tiempo y espacio- es una forma de esa explotación. 
Redefiniciones dusselianas: aportes para concebir una biopolítica decolonial. - la relación política-poder-vida que analiza Dussel y que Flores toma como punto de anclaje para concebir la idea de biopolítica decolonial, es manejada desde distintos contextos históricos revolucionarios de Latinoamérica, aquí Dussel resalta la llegada al poder de Morales en Bolivia y califica como un golpe descolonizador -Evo Morales es indio-, y el momento de posesión indígena un día antes de la posesión de presidente, es considerado por Flores y Dussel como la impronta ancestral que rompe la hegemonía eurocéntrica, aquí se denota que la colonia no pudo romper la tradición indígena o fue un acto de rebelión esperado por tantos y tantos años, -Flores lo llama racismo epistémico que fue humillado por la episteme ancestral de los indios bolivianos-. Dussel para pretender lograr las transformaciones emancipatorias se permite, según Flores: llamar corporalidad viviente al ser humano; plantear reconceptualizar el poder, mediante una definición que remplace lo que se entiende por poder, para Dussel “el poder es voluntad de vida"; lograr la factibilidad para contar con los medios necesarios. Estas tres características permiten esgrimir una definición "el poder político es voluntad acordada factiblemente".

Flores analiza a Dussel desde los modos de poder planteados por el filósofo: poder negativo que es el poder sobre los otros y poder creador positivo que es el poder anterior y sobre el podersobre. Este último es decolonial y se trata de un poder que aún es débil, pero está presente en las comunidades críticas. Si este poder positivo permite pensar y actuar entonces es un biopoder decolonizador enfatiza Flores.

Conclusiones provisorias. - Flores concluye que el auténtico trasfondo de la colonialidad es la colonización de la vida humana. Vincula la vida-poder-política para presentar un proyecto biopolítico decolonial -descolonizar al ser viviente colonizado-, para finalizar Flores cita otra vez a Dussel, (2001) "No se trata de un proceso de inclusión, sino de creación novedosa, analógica, transformadora. No es cuestión de hacer simplemente una nueva habitación para los excluidos en la antigua casa. Es necesario hacer una nueva casa, con nueva distribución, de lo contrario los indígenas, las mujeres y los afroamericanos irán a las habitaciones 'de servicio'... como antes, como siempre” (pág. 317) y enfoca esta cita a la decolonización de la educación. La educación no puede ser excluyente, esta es la denuncia decolonial, que la pseudo-inclusión ha sido dominación. Termina Flores indicando que la vida es el punto ontológico de una política de liberación, de una 
pedagogía decolonial. Es a la corporalidad viviente intersubjetiva a la que intenta empoderar este enfoque decolonial.

\section{Decolonizar la universidad}

Santiago Castro Gómez realiza un estudio de la incidencia de la colonialidad del saber latinoamericano sobre la universidad y la urgente necesidad de decolonización de la academia mirando la evolución histórica que esta ha tenido y el planteamiento de algunas alternativas para lograr el propósito. Analiza las características y rasgos principales como la herencia colonial y la hegemonía eurocéntrica -planteadas por Lander -, denominada la hybris del punto cero. Reflexiona sobre la decolonización de la universidad y se funda en paradigmas subalternos de pensamiento no occidental que puedan provocar rupturas de la lógica colonial, además estudia tres puntos en los que basa la colonialidad que son: la colonialidad del ser, saber y poder, en donde el poder subordina al ser y al saber, aquí el autor enfatiza que son las relaciones de poder las que gestionan el sistema político, económico y social, encauzando al sujeto a ser, sujeto político-social para alinearlo en las dinámicas de poder.

Como se menciona en el párrafo próximo anterior, Santiago Castro invita a plantear alternativas decoloniales que rompan el sistema hasta hoy arraigado en el consciente y subconsciente de los sujetos, para de esta forma generar epistemológicamente paradigmas sólidos o a su vez, que se puedan unir con paradigmas ya instaurados a fin de acercarse al objeto de conocimiento. En este contexto al ser la universidad la productora de un saber fresco y actualizado, y ser por antonomasia el nicho ideológico y de construcción de los paradigmas epistémicos modernos que permiten el desarrollo de las condiciones más favorables de la sociedad.

La universidad, indica Santiago Castro se desarrolla en torno a dos modelos: el de incorporación del conocimiento del objeto que permita el desarrollo estatal a través del bienestar material y, la formación de sujetos capaces de educar en valores -estos permiten dar cumplimiento a los objetivos de la modernidad- y humanismo.

Castro enuncia el problema del modelo universitario y este lo relaciona con la hybris del punto cero, -la hybris del punto cero se ubica en la modernidad-colonialidad en donde permanece arraigado el imaginario universal de superioridad eurocéntrica hacia el resto del mundo-, que 
mediante un constructo colonial epistémico subordina el conocimiento ancestral -precolonial- de los pueblos. Con la creación del Estado contemporáneo la universidad pierde su protagonismo, debido a que el conocimiento que está en las aulas ya no es exclusivo de ellas, sino que, entra al servicio del sistema político del momento -capitalismo global-. Con la necesidad del Estado de aumentar la producción empieza la prostitución del conocimiento para la creación de las empresas que se alistan a competir -sistema capitalista-, apareciendo la biopolítica -ya explicada en párrafos anteriores, el biopoder- y con ello la perdida de la esencia de la universidad formación de sujetos críticos- quien se somete al Estado y se convierte en su instrumento de generación de mano de obra cualificada para la competición-producción-consumo.

Santiago Castro sostiene firmemente que, con la privatización de la enseñanza universitaria, se pierde el fin social para el que fue creada la universidad, y que es el Estado el responsable de esta execración de la universidad que es profanada con alevosía política-económica por el biopoder el sistema enarbola instancias que conllevan a la profundización del modelo, no aceptando proyecciones que vayan por un camino diferente-. Por lo tanto, infiere Castro, pensar diferente a las políticas del Estado se transforma en algo marginal.

El autor presenta alternativas atinentes a la decolonización de la universidad, una de ellas es la hybris del punto cero, la misma que se constituye en una estructura epistémica programática de la universidad y en la profundización de las disciplinas, mediante la transdisciplinariedad -implica un programa universitario flexible, sin límites estrechos- que permita el diálogo de saberes desde la horizontalidad de las disciplinas, lo cual permitirá, la deconstrucción de la universidad mediante la decolonización de los saberes disciplinares. Con la transdisciplinariedad, Castro invita a la transculturalidad -basándose en el pensamiento complejo-, con esto destierra los obstáculos epistemológicos y acerca el conocimiento universal a cada contexto, lo que pretende es no retornar a cero, sino, que desde donde este el conocimiento se empiece como punto de partida.

Es la universidad el lugar desde donde se puede decolonizar el saber, pero existen movimientos los grupos de poder dominantes- sociales que generan instancias paralelas que transitan y obstaculizan el saber emancipado que pretende gestar la universidad en contraposición de los paradigmas epistémicos eurocéntricos y con ello no se puede producir el diálogo de saberes. Pero 
Santiago castro pregunta ¿qué significa decolonizar la universidad en América Latina? Aunque esta interrogante la coloquemos al final del estudio de Castro Gómez, se lo hace con la intención de saber si la mirada que tenemos del mundo puede estar alienada por una herencia colonial o, si al contrario se puede hablar de una autonomía cognitiva alejada epistemológicamente del modelo epistémico occidental desplegado por la modernidad occidental.

\section{Decolonizar el saber, reinventar el poder}

El análisis y reflexión de Boaventura Do Santos, (2010) En su obra "Decolonizar el saber, reinventar el poder", toca sin anestesia el tema de la descolonización epistemológica, social, económica, política, religiosa y cultural de los pueblos colonizados del Sur, e imbrica con otras obras sobre el tema para fortalecer su discurso. La descolonización mental y de las prácticas sociales subyacen en el trabajo del portugués. La obra está inscrita en un pensamiento emancipatorio arraigado del autor desde sus estudios poscoloniales -aunque los realice en Europa, tiene un claro tiente de pensamiento de frontera lo que permite el entendimiento del diálogo de saberes, lenguajes, culturas, contextos temporo-espaciales del mundo-, es lo que hoy se conoce como la epistemología del sur desde donde se visibiliza la invisibilización que desde hace más de 500 años ha existido por parte de un eurocentrismo -en lo que a América se refiere- que no ve más allá de los intereses occidentales que mediante la explotación y opresión histórica han logrado abrir una brecha abismalmente grande -colonialismo y capitalismo-.

Santos abre un abanico cargado de insumos teóricos bien fundados para el debate con la consigna de -pensar- descolonizar lo colonizado y aterrizar en un nicho de interculturalidad de liberación de los pueblos subalternados. Una liberación cognitiva, lenguaje, social, económica, política, religiosa, espiritual heredada desde Europa con pinceladas de modernidad y progreso que nos fueron impuestos a golpe de bayoneta y fusil. Este abanico permite repensar las relaciones de interculturalidad que permitirán a su vez combatir la neoexplotación neocolonial que se arraiga en el subconsciente de los latinoamericanos -deberíamos llamarnos indios de las américas-.

Es importante, elevar una crítica severa y fundada, mantiene una postura epistémica coherente y pertinente, que rompe los esquemas occidentales, que nos mantienen auto-subestimados -la enajenación nos auto clasifica en: inferiores a los otros, en que debemos ser los dominados por 
los otros-, la obra es por tanto un justo reclamo de descolonización global del conocimiento del objeto, la política, el ser y, amén de esto, es una apuesta por la construcción de espacios plurales de diálogo desde donde construir en conjunto el valor de la unidad en la diversidad -la praxiología de la tolerancia, mestizaje, solidaridad e interculturalidad de y entre los pueblo-, de los pueblos poscoloniales.

Des-pensar para poder pensar. Es clara la idea que plantea Do Santos al enunciar que el problema tiene dos vertientes teóricas de corte ideológico-político: pensar en el final de un capitalismo que no tiene fin y pensar en un colonialismo que no tiene fin. El autor pone en tela de duda nuestra capacidad para desarraigar el sistema capitalista y los rezagos del sistema colonial -almacenados en nuestro subconsciente-, para que esto se pueda pretender lograr, indica una opción epistemológica y política "pensar desde el sur", para ello acude a los estudiosos que forman los grupos de subalternidad con posturas antagónicas a: las concepciones filosófica-políticas que flotan desde occidente hacia nuestra vera -el sur- y a aquellas teorías críticas que emergen desde el sur pero son pensadas con tinte del norte. Para que se produzca esta postura es preciso añade el autor desarrollar una "sociología transgresiva", de las ausencias y las emergencias. La sociología de las ausencias es la encargada de hacer visible -lo invisible desde el rescate de los conocimientos ancestrales-, el objeto del conocimiento solapadamente oculto por occidente tras años de colonialismo y poscolonialismo. La sociología de las emergencias por su parte busca como su nombre lo indica detectar alternativas sociales que permitan cambiar el presente y con planteamientos prospectivos desde este presente, caminar al futuro con autonomía cognitiva.

Más allá del pensamiento abismal: de las líneas globales a una ecología de saberes. El pensamiento abismal es una teoría que de Sousa trabaja para identificar aquellas características del pensamiento moderno occidental, este pensamiento que hace distinciones visibles humanidad, sociedad civil, metrópoli, hegemonía de los saberes-, e invisibles -estado de natura, zona colonial, saberes subalternos e inhumanidad-. Este pensamiento a su vez es el que divide imaginariamente al norte del sur, un norte: colonial, explotador, dominante, y un sur: oprimido, explotado en la colonia y postcolonia -situado en la línea abismal-. Para solventar esta desigualdad social llena de exclusiones, gestadas desde ese pensamiento abismal Santos funda desde el "pensamiento postabismal" la teoría postcolonial, una teoría -que se inscribe y pone su 
marca- desde el otro lado de la línea. Es desafiar las leyes de la razón -colonial o postcolonial- y desafincar las prácticas monoculturalistas occidentales agresoras con el sur con la puesta en marcha de una sociología -filosofía transgresora- desde las emergencias para revalorizar las multidimensionales experiencias humanas del sur, en antagonismo con la sociología de las ausencias, única culpable -dentro del contexto multidimensional- del desperdicio de esas experiencias que pudieron ser el alimento espiritual y humano -de la otra sociedad- para occidente, de Sousa quiere sentar una serie de contratos sociales que sirvan para representar valores universales ninguneados por el eurocentrismo colonial y poscolonial, rompiendo para siempre ese pensamiento abismal.

Lo que propone de Sousa es una praxiología epistemológica -mediante el procedimiento mismo de objetivación de la acción, es decir la teoría de la acción; desde el conocimiento que la teoría es estéril cuando la práctica es ociosa, haciendo conciencia del pensamiento y la acción que sigue al acto de pensar, en donde el actor es el que piensa, el pensador es el que actúa con libertad porque su pensamiento lo ha hecho libre- desde la "ecología de los saberes", es decir una acción dialógica e intercultural con reconocimiento a la pluralidad de los saberes heterogéneos, acción que permite la interrelación trasversal de los saberes, y mengua la idea que "la comprensión del mundo es mucho más amplia que la comprensión occidental del mundo" -pág. 8 9-, Boaventura defiende la diversidad epistemológica del mundo en el contexto particular de cada pueblo y promueve mediante esta ecología de los saberes valores de justicia, democracia y solidaridad cognitiva.

La concepción que tiene de Sousa sobre los derechos humanos, es matricial con claro sesgo occidental y liberal, discriminando y situando por enésima vez en esa línea abismal al sur -sin situar al ente de occidente en la otredad -. Los derechos humanos son localismos globalizados por todo el mundo. Aquellas pretensiones pseudouniversalistas y cargadas de una retórica sobre los derechos humanos, no hace sino, entender a de Sousa que son letras discursivas de propaganda sobre la idea y los valores del mundo occidental -con un marcado individualismo egoístacapitalista-democrático-progresista-. Se debe entonces hacer una reconstrucción de los derechos humanos desde la interculturalidad universal global localizada y no desde el localismo occidental globalizado que sólo permite ver que es un instrumento del imperialismo cultural. 
Lo que Santos de Sousa propone es diseñar una "política contrahegemónica de derechos humanos" (pág. 67) mediante un planteamiento filosófico intercultural -traducción intercultural-, como arjé de partida, este es a criterio de Santos un procedimiento de comunicación que admite la creación de una inteligibilidad recíproca en la búsqueda de espacios que puedan resultar comunes, estableciendo alianzas para la resistencia en la que participen muchas culturas y movimientos u organizaciones sociales. Esta política contrahegemónica se debe fundar en una propuesta epistemológica que aspire a la construcción colectiva, diversa y proactiva de saberes y prácticas,

Boaventura de Sousa crítica y dialoga desde una postura reflexiva -en contra del dominio global de unos determinados patrones culturales y su imposición obligatoria desde occidente-, creativa y solidaria y apuesta por un proyecto intercultural postcolonial, siempre dialógico y mestizo, fundado en una racionalidad comunicativa y cosmopolita que no desperdicie los conocimientos ni las experiencias como alternativa pacífica -en contraposición de la reproducción del sistema de explotación colonial globalizante neoliberal-. Trabajar desde la ecología de los saberes en ese proyecto crítico y alternativo para descolonizar y trasformar a su vez la sociedad -aún colonial y capitalista-.

\section{Análisis temático}

Los temas que se eligieron para el estudio tienen una interrelación que se sustenta en el pensamiento decolonizador de los autores, ellos desde su óptica muy particular, presentan un enfoque común de lo que es hasta el día de hoy la colonialidad en el Sur de parte del occidente.

Partiendo desde Grosfoguel (2006) que mantiene un discurso subalterno de principio a fin desde el cual analiza las formas de colonialismo, colonialidad y los efectos colaterales que han trascendido hasta nuestros días, efectos como la pérdida de identidad y el mestizaje cultural que se presenta hoy como natural, incluso por parte de los llamados a levantar la voz epistémica que libere el conocimiento y la universalidad del saber sin esconderse y presentando una identidad sin matices eurocéntricos. Rompiendo desde este posicionamiento epistémico, la matriz del sistema mundo moderno/colonial/capitalista/patriarcal. Empresa muy difícil de conseguir si se tiene en cuenta que hemos pasado en estos más de 500 años del colonialismo global a la colonialidad 
global, es decir nos independizamos de los colonizadores, pero quedó los rasgos del colonialismo -postcolonialidad- impregnados en nuestro más profundo subconsciente y eso nos hace seguir siendo del Sur, lo que debemos es tener un pensamiento fronterizo en donde cohabitemos con respeto a las características particulares desde una visión universal.

A este pensamiento se une el de Flores, que ya instala a la educación como artífice de decolonialidad o, que invita a la decolonialidad de la educación y a través de esta -la educación-, a la recuperación de la dignidad vital del sujeto, la autora coincide con Grosfoguel (2006) en que es preciso desarraigar los atisbos de colonialidad, ya que estos afectan la Bios del ser humano. En esta parte nosotros coincidimos con la autora en la parte que señala al biopoder como el sistema de control del ser humano por parte del Estado, mediante la biopolítica-que viene a ser lo mismo-, e invita a la educación a involucrarse en una transmodernidad descolonizadora. Flores coincide con Castro Gómez en cuanto a la colonialidad del poder y nosotros coincidimos con ellos, es preciso poner en práctica biopolíticas decoloniales masivas desde las aulas -los docentes debemos decolonizarnos para decolonizar a los estudiantes-, con epistemes decolonizadas y construidas desde el Sur, sin que con esto se pretenda ser dueños de la verdad o el conocimiento. Para cumplir este cometido es preciso entonces aprender a auto-hetero-decolonizarnos y formar con la descolonización -citando a Fanon- "hombres nuevos", para ello es preciso que los docentes -no todos estarán de acuerdo-, presentemos un proyecto biopolítico y educativo -agregamos nosotros- decolonial.

Decolonizar la universidad, es la propuesta de Santiago Castro Gómez, es un tema álgido que por responsabilidad social debemos tratar ¡ahora!, llega la interrogante ¿cómo decolonizar la universidad -ecuatoriana para el caso que nos ocupa-? Existen paradigmas subalternos muy bien estructurados y fundados, pensamientos de grupos subalternos que nos hacen a nosotros también pensar que es posible dar el salto de paradigma de la colonialidad del ser, saber y poder a la decolonización del saber universitario y con ello la decolonialidad del ser, saber y poder. Es aquí donde estamos seguros que debe entrar la docencia universitaria y desde estos, la reconceptualización de la misión que tiene la universidad para con la sociedad, que es la generación de saberes libres - desde la transdisciplinariedad y con esta la transculturalidad- para la vida y no para la producción y el consumo -herencia colonial-. 
Una vez que hemos hilvanado los pensamientos de Grosfoguel (2006), Flores y Castro, para hacer ese tejido conceptual que pretendemos, nos toca fortalecerlo con el "Decolonizar el saber", y el "reinventar el poder", de Boaventura do Santos. Aquí logramos entender, que es una imperiosa necesidad dialéctica la descolonización epistemológica, social, económica, política, religiosa y cultural de los pueblos colonizados de Sur. Sin embargo, ¿podemos desarraigar ese modelo impuesto durante cientos de años? Al igual que la interrogante de Santiago Castro, nos queda la duda que podamos desalienar nuestra mente sin el debido proceso de empoderamiento metacognitivo del decolonialismo del conocimiento, hay que "penar desde el Sur" y esa es la propuesta decolonizadora de los cuatro autores, el primero y el último desde un enfoque multidimensional y, Flores y Castro desde un enfoque educativo. Para lograr esto, es necesario que desarrollemos alternativas untadas con la sociología de las emergencias para hacer visible aquellas ausencias que durante cientos de años han estado, pero han sido invisibilizadas por el saber occidental y superpuesto a este, por el biopoder occidental con biopolíticas neocolonizadoras generadas desde ese pensamiento abismal -líneas imaginarias que dividen el Norte y el Sur-.

\section{Perfil de fortalezas y debilidades}

Los documentos analizados nos permiten visualizar algunas fortalezas que estos tienen: enfoque claro de los objetivos, posicionamiento epistemológico, propuestas subalternas definidas, pensamiento multidimensional universal-local. Dentro de los objetivos de los autores, estos tienen un común denominador: decolonizar el saber para decolonizar el poder.

Las debilidades que presentan en común son a criterio muy particular en el caso de Grosfoguel (2006), Flores y Castro es que denotan debilidad al levantar la voz de reclamo de esa decolonización, Flores por ejemplo se maneja en el decir de Fanon y Dussel pero no se decoloniza de esos pensamientos, es decir, proponen la decolonización pero se mantienen colonializados por nuevas corrientes y no presentan una carta e identidad epistemológica que les permita ser y estar en autonomía cognitiva -claro está desde los requisitos previos que han logrado adquirir en base a sus estudios-, ¿cómo decolonizar la docencia universitaria ecuatoriana?, sigue allí la gran interrogante. 


\section{Conclusiones}

Los autores traídos a diálogo permiten realizar un análisis sobre el tema de estudio que es la descolonización del saber -y el poder- para la decolonización de la universidad ecuatoriana, es un tema que a nosotros como docentes universitarios nos preocupa. Interrogantes como ¿Cómo decolonizar la docencia universitaria ecuatoriana? ¿está el docente universitario ecuatoriano decolonizado en el saber? ¿podemos decolonizar el saber para decolonizar el poder?

El arjé del mundo construyó sus bases filosóficas en saberes cargados de reciprocidad, solidaridad y visión multidimensional del cosmos, estas bases fueron rápidamente corroídas por los grupos de poder en cada contexto temporo-espacial de lo que tenemos memoria histórica. Las formas de colonización y explotación se encuentran desde siempre, para el tema que nos ocupa sobre la colonialidad y postcolonialidad de parte de occidente y las alternativas de decolonialidad que invitan los autores a poner en práctica, nos permiten concluir bajo los siguientes puntos:

Existe claros indicios de que se puede descolonizar la economía política desde un pensamiento fronterizo -también es evidente que no existe una postura epistemológica decolonizada en los docentes universitarios-, desde la decolonización de la Bios del Ser que plantea Flores para lograr la decolonización de la universidad que invita a trabajar Castro. Para que esto se pueda generar hace falta por supuesto decolonizar el saber y reinventar el poder.

La vida del ser humano es vivir en libertad y es inalienable y se constituye en un derecho universal inscrito en la carta de los derechos humanos que nos manifiesta que "nacemos libres e iguales en dignidad...", "todo individuo tiene derecho a la vida, a la libertad...", "nadie estará sometido a esclavitud ni a servidumbre...", "nadie será sometido a torturas ni a penas o tratos crueles, inhumanos o degradantes", "toda persona tiene derecho a la libertad de pensamiento, de conciencia y de religión...", "toda persona tiene derecho al descanso, al disfrute del tiempo libre, a una limitación razonable de la duración del trabajo y a vacaciones periódicas pagadas". Tan solo por citar algunos principios que encontramos en esa carta, pero... ¿se cumplen o han cumplido estos derechos?, ¿acaso no hemos vivido una constante y prolongada esclavitud? y cuando esta se prohibió ¿no se crearon nuevas formas de esclavitud, como es el caso del trabajo organizado?, ¿acaso los docentes ecuatorianos no trabajamos más de 40 horas semanales? 
El decolonizar el saber solo será factible en día que se geste una postura epistemológica pertinentemente estructurada por parte de los grupos subalternos del Sur, desde el Sur y para el Sur, si se logra decolonizar el saber y se logra hacerlo universalmente aceptado -aunque eso no signifique practicado-, se habrá dado el salto anhelado -no un salto del Sur al Norte- y pasar de la explotación y dominación a la libertad y autonomía cognitiva. En el momento en que se decolonice el saber, se podrá también desde esa postura independiente diseñar una estructura de poder positiva para vivir bajo el paraguas del Sumak Kawsay que practicaban nuestros ancestros.

Decolonizar la docencia universitaria ecuatoriana NO es posible. Esa es la conclusión a la que llegamos después del análisis e interpretación de las lecturas de los autores. No podemos decolonizar la docencia universitaria ecuatoriana porque no tenemos identidad académica, no tenemos un perfil epistemológico que nos permita diseñar currículos independientes del sistema Estatal, eso nos hace ser vulnerables y subordinados a hojas de ruta preestablecidas por los grupos de poder y estos a su vez, importan currículos neocolonizantes desde occidente con lo cual quedamos otra vez bajo la tutela eurocéntrica.

\section{Referencias Bibliográficas}

Acosta, A. (2013). El Buen Vivir. Sumak Kawsay, una oportunidad para imaginar otros mundos. Barcelona, España. Recuperado el 4 de enero de 2018

Boaventura Do Santos, S. (2010). Descolonizar el saber, Reinventar el poder. Montevideo, Uruguay: Ediciones Trilce. doi: ISBN: 978-9974-32-546-3

Borinosik, H., \& Beresñak, F. (2012). Bíos y zoé: una discusión en torno a las prácticas. Astrolabio. Revista internacional de filosofía (13), 82-90. doi: ISSN 1699-7549

Castro Gómez, S. (2007). El giro decolonial. (S. Castro-Gómez, \& R. Grosfoguel (2006), Edits.) Reflexiones para una diversidad epistémica más allá del capitalismo global, 308 (79). Recuperado el 2 de enero de 2018, de http://arquitecturadelastransferencias.net/images/textos/elgiro-decolonial.pdf\#page $=79$ 
Castro Gómez, S. (2010). La hybris del punto cero: ciencia, raza e ilustración en la Nueva Granada (1750-1816). (I. Pensar, Ed.) Bogotá, Colombia: Editorial de la Pontificia Universidad Javeriana. doi: ISBN 9789586838085

Dussel, E. (2001). TRANSMODERNIDAD E INTERCULTURALIDAD. Obtenido de transmodernidad e $\quad$ interculturalidad $\quad-\quad$ Enrique Dussel: http://enriquedussel.com/txt/TRANSMODERNIDAD\%20e\%20interculturalidad.pdf

Fanon, F. (1983). Los condenados de la tierra (Séptima reimpresión ed.). (J. Campos, Trad.) Francia: FONDO DE CULTURA ECONÓMICA. doi: OCLC: 11787563

Flores, O. (1999). OCTAVIO PAZ: LA OTREDAD, EL AMOR Y LA POESÍA. Razón y Palabra (15). Recuperado el 5 de enero de 2018, de http://www.razonypalabra.org.mx/anteriores/n15/oflores15.html

Flores, G. (2014). Bios, poder y política. Una perspectiva desde el enfoque decolonial. Educación, 07-04-06(7), 427-444. Recuperado el 9 de enero de 2018, de fh.mdp.edu.ar/revistas/index.php/r_educ/article/download/1001/1042

Foulcaut, M. (1976). Historia de la sexualidad. Uruguay. Recuperado el 7 de enero de 2018, de http://www.uruguaypiensa.org.uy/imgnoticias/681.pdf

\section{Grosfoguel (2006), R. (2006). LA DESCOLONIZACIÓN DE LA ECONOMÍA POLÍTICA Y} LOS ESTUDIOS POSTCOLONIALES: Transmodernidad, pensamiento fronterizo y colonialidad global. Centro de Estudios Latinoamericanos (4), 17-48. Recuperado el 5 de enero de 2018, de biblioteca.clacso.edu.ar/Panama/cela/20120718102251/descolonizacion. pd

Iudin, P. F., \& Rosental, M. M. (1946). Diccionario filosófico marxista. Montevideo, Uruguay: Unidos, Ediciones Pueblos. Recuperado el 4 de enero de 2018, de http://www.filosofia.org/urss/dfm1946.htm

Lander, E. (2000). ¿Conocimiento para qué? ¿Conocimiento para quién? Recuperado el 2 de enero de 2018 , de http://www.ulpiano.org.ve/revistas/bases/artic/texto/RDUCV/124/rucv_2002_124_99-126.pdf 
lleras, E. (2010). Del educar al pedagogiar. Polis, Revista de la Universidad Bolivariana, 9(25), 235-242. doi: ISSN: 0717-6554

Quijano, A. (2000). Quijano, Aníbal. Colonialidad del poder, eurocentrismo y ... - Clacso. (CLACSO, Ed.) Recuperado el 5 de enero de 2018, de bibliotecavirtual.clacso.org.ar/ar/libros/lander/quijano.rtf

Tranier, J. (2017). Nuevos Escenarios de la Educación Contemporánea. Apuntes del seminario, Universidad Nacional de Rosario, Rosario. Recuperado el 5 de enero de 2018 